Tilman Santarius, Christof Arens, Urda Eichhorst, Dagmar Kiyar, Florian Mersmann, Hermann E. Ott, Frederic Rudolph, Wolfgang Sterk, Rie Watanabe

\title{
Pit Stop Poznan. An Analysis of Negotiations on the Bali Action Plan at the Stopover to Copenhagen
}

Originally published as:

Tilman Santarius, Christof Arens, Urda Eichhorst, Dagmar Kiyar, Florian Mersmann, Hermann E. Ott, Frederic Rudolph, Wolfgang Sterk, Rie Watanabe (2009):

Pit Stop Poznan. An Analysis of Negotiations on the Bali Action Plan at the Stopover to Copenhagen

In: Journal For European Environmental \& Planning Law (JEEPL), 6.1, 75-96 
Tilman Santarius ${ }^{a^{*}}$, Christof Arens ${ }^{a}$, Urda Eichhorst ${ }^{a}$, Dagmar Kiyar a , Florian Mersmann ${ }^{\text {a }}$, Hermann E. Ott a, Frederic Rudolph ${ }^{\text {a }}$, Wolfgang Sterk ${ }^{\text {a }}$, Rie Watanabe ${ }^{\text {a }}$

Pit Stop Poznan. An Analysis of Negotiations on the Bali Action Plan at the Stopover to Copenhagen

a Wuppertal Institute for Climate, Environment and Energy, Germany

* Corresponding author: Tilman Santarius

E-mail: tilman@santarius.de 


\section{Abstract}

This paper analyzes the international climate negotiations that took place at the $14^{\text {th }}$ Conference of the Parties to the UNFCCC (COP) and the $4^{\text {th }}$ Meeting of the Parties to the Kyoto Protocol (CMP) held in Poznan, December 1-12, 2008. It works out the main issues at stake in the negotiations, contrasts divergences in interests amongst negotiating Parties, and summarizes the main results achieved in Poznan. Furthermore, it contextualizes the Poznan negotiations within the broader political and economic context, which has shaped climate policy making throughout 2008. The paper ends with an outlook on the tasks ahead in 2009, until the next COP/CMP in December 2009 in Copenhagen.

Keywords: Climate Policy, International Agreements, Kyoto Protocol, UNFCCC, Post-2012

\section{Introduction}

As the half-way mark of two years of negotiations between the conference in Bali in 2007 and the upcoming Copenhagen conference in 2009, Poznan merely was a pit stop. Pit stops have importan functions - namely to fill up the reserves and to chart the course anew. However, this $14^{\text {th }}$ Conference of the Parties to the UNFCCC (COP) and the $4^{\text {th }}$ Meeting of the Parties to the Kyoto Protocol /CMP) barely produced any remarkable results. In Copenhagen, eventually, Parties will (have to) agree upon a new multilateral climate change agreement for the time after 2012 without much help from the Poznan conference.

It could have been worse, however. True, Poznan did not deliver any breakthroughs, nor did it display the political leadership and determination necessary to achieve an ambitious and robust agreement within the one year that is left. On the other hand, Poznan did not experience any major backslides either, which it could have. For in the shadow of the financial crisis, the political environment had changed significantly over the last months - to the detriment of climate policy.

The year 2007, which gave birth to the historic Bali Action Plan, may in retrospect be called the "year of the climate": the Nobel Peace Prize had been awarded to the Intergovernmental Panel on Climate Change (IPCC) and Al Gore; an unprecedented number of high-level diplomatic meetings dealt with climate change, such as the G8 summit or the special sessions of the UN Security Council and the General Assembly; and press and media awareness on climate issues had been as high as never before in many countries of the world. 2008, however, witnessed a downturn. In particular, public fear of a pending economic recession gave sufficient leeway to those questioning the necessity of climate policies. Calls on politicians to secure jobs and fight unemployment with gigantic economic stimulus packages displaced climate issues from the main political concerns. Italy's prime minister Berlusconi even suggested: "I think it is absurd to talk about emissions cuts in this crisis moment. It is as if someone suffering from pneumonia were to think of going to the hairdresser." ${ }^{\text {Fortunately, a number }}$ of ministers in Poznan emphasized that investing in low-carbon economic development does not only contritbute to saving the biosphere, but also offers a first-best solution to fighting unemployment and spurring growth. Mitigating climate change thus ruther resembles insulating a house in order to prevent the people from catching pneumonia in the future.

Actual negotiations during the Poznan were additionally affected by the tug-of-war over the European climate and energy package. For many observers present in Poznan, it seemed as if the really important negotiations did not take place there, but in Brussels. Deep divergences between Eastern,

\footnotetext{
${ }^{1}$ Berlusconi said so at the side of negotiations on the European climate and energy package. See www.fossil-of-the day.org/go/.
} 
Southern and Western European member states mirrored the challenges faced by the negotiations on the multilateral level. An the watering down of the EU package even by countries such as Germany or Swedenm which had been known as front-runners on climate policies, casts a cloud on what may happen in Copenhagen in the absence of strong political leadership.

In light of these suboptimal political circumstances, it was most pleasing to see developing countries demonstrating significant leadership in climate policy development. South Africa, China, Mexico, and South Korea in particular have drafted ambitious climate policy legislation at the national level. South Africa has announced to put forward additional and even more ambitious legislation if there was adequate support by the international community. Yet not only at the national level, but also within the international negotiations, developing countries have demonstrated considerable leadership. In fact, with the European Union tied-up in its battle over the EU climate and energy package and the new US-administration not yet in the starting blocks, the developing countries were the only driving force behind negotiations before and during Poznan. Throughout 2008, several of the most progressive proposals, such as on technology development and transfer, or on finance mechanisms, were submitted by individual developing country Parties or the G77+China as a group. And during the Poznan conference, developing countries were indeed the only ones that built up pressure on a number of issues, such as on financing adaptation, or on defining an aggregate long-term emissions reductions goal for industrialized countries.

Alas, developed countries' positions for Poznan were weak, and neither the EUnor theUmbrellaGroup were ready to discuss concrete emissions reduction obligations for themselves, or the scope of financial and technological support for the South. As a result, the Poznan conference produced the bare minimum of what was needed to keep the process moving. Soon negotiators may come to regret this, since the lack of any real progress in Poznan of course puts additional pressure on upcoming meetings. Yet the timing of negotiations until Copenhagen is extraordinarily tight, and the agenda is becoming ever more complex.

Already the scope of the agenda for Poznan was impressing, with six bodies considering more than 90 agenda items and sub-items. Because of the 'low energy' of negotiations, a number of less urgent agenda items were not even given attention. The two Ad hoc Working Groups - on Long-term Cooperative Action (AWG-LCA) and on Further Commitments by Annex I Countries under the Protocol (AWG-KP) - did not deliver more than a work plan for 2009. Neither the ambition for domestic mitigation nor for South- North cooperation on finance or technology have seen any progress since the Bali conference in 2007. And while the second review of the Kyoto Protocol under its Article 9 stimulated some worthwhile discussions, it was in the end concluded without any decisions.

The conference, however, did deliver some results, such as the full operationalization of the Adaptation Fund. In addition, some achievements were made in the Subsidiary Bodies on Implementation (SBI) and on Scientific and Technological Advice (SBSTA). Regarding the day-today operation of the climate regime, some progress was possible in improving the methodologies of the Clean Development Mechanism (CDM).

\section{Mitigation}

Discussing by how much countries have to reduce their greenhouse gas emissions naturally lies at the hear of the climate negotiations. Due to the architecture constructed by the Bali Action Plan, these negotiations take place in both Ad hoc Working Groups (AWGs). Therefore, industrialized countries emphasized the need to maintain coherence between both of the AWGs and to follow an interative approach. New Zealand with support of other Umbrella Group countries even proposed to convene a Committee of the Whole bringing together the two AWGs in Junge 2009. 
Yet developing countries insisted on keeping the AWGs separate and were in favor of sequencing: They maintained that the aggregate level of post-2012 Annex I targets discussed in the AWG-KP should be decided first, preferably already in Poznan, in order to then move on to individual targets. In particular, developing countries highlighted the IPCC Fourth Assessment Report (AR4) and called for an overall Annex I reduction of "at least" $25-40 \%$ below 1990 levels by 2020 . In their words, the AWG-KP was the "channel to show leadership".

However, the issue of the aggregate Annex I target proved to be as contentious as ever. In AWG-KP discussions, the EU, Norway and Switzerland reiterated their commitment to the $25-40 \%$ range, but this range continued to be resisted by Australia, Canada, Japan, New Zealand, Russia and the Ukraine. Russia even rejected such a top-down approach in principle, emphasizing its national circumstances. Instead, Russia insisted, individual country commitments should be determined, which would then add up to an aggregate commitment.

In the end, the final AWG-KP text reads like a copy from the text accomplished last year in Bali. It addresses both the aggregate range and individual commitments, but without clarifying the relationship between the two. On the aggregate level, the text notes that further consideration should be informed by recent scientific information, including the IPCC AR4, andmentions the $25-40 \%$ range. In addition, the text notes existing pledges for commitments and invites submission of information on possible commitments. The Parties in Poznan did, however, agree that future commitments should "principally" take the form of quantified emission limitation and reduction objectives (QELROs). The AWG-KP conclusions also note that emissions trading, the project-based mechanisms and LULUCF should continue to be available to Annex I Parties as means of compliance. $^{2}$

In the Ad hoc Working Group on Long-term Cooperative Action (AWGLCA), the issue of mitigation was discussed along the negotiations on a "shared vision", which includes global mid- and long-term emissions reduction goals. The basis for negotiations was a draft "assembly text" tabled by the Chair a few weeks before Poznan. Structured along the building blocks of the Bali Action Plan, this text put together the variety of country submissions received throughout 2008. During Poznan, an updated version of the assembly text has been provided, now comprising 164 submissions. ${ }^{3}$ This text will form the basis for the upcoming negotiations in early 2009 .

Although Parties agree that a long-term emissions reduction goal is necessary, it may take until the Copenhagen conference to agree upon a concrete number. Nevertheless, a positive sign in Poznan was that Switzerland, Mexico and Korea have joined the European Union, Norway, Iceland, the African States, and Chile in officially supporting the $2{ }^{\circ} \mathrm{C}$ target. The Alliance of Small Island States (AOSIS) has now even started to demand a $1,5^{\circ} \mathrm{C}$ target, as several of their islands will already be flooded at a warming of two degrees. This allows for some hope that in the end, the global emissions reductions goal will be sufficient to prevent dangerous interference with the global climate system.

An intensive debate evolved around possible contributions from developing countries. Parties considered the idea of establishing a registry of "nationally appropriate mitigation actions" (NAMAs) in developing countries. Brazil agreed that the registry should bring actions and resources together, yet several countries demanded that this must be voluntary. While the EU suggested registering outcomes of actions as well, India stressed there should be no review of adequacy of developing country actions. Several countries of the South rejected the EU's suggestion to define an aggregate emissions reduction goal for developing countries in terms of a quantified deviation from business-as-usual.

Instead, they referred to the historical responsibility of Annex I countries and even questioned the fairness of the emissions reductions ranges for developing countries suggested by the IPCC.

As throughout all negotiations in 2008, the sensitive issue of differentiation among developing

\footnotetext{
${ }^{2}$ FCCC/KP/AWG/2008/L.18.

${ }^{3}$ FCCC/AWGLCA/2008/16/Rev.1.
} 
countries was bypassed again during the talks in Poznan. The G77+China usually tend to circumvent the issue to maintain coherence as a negotiating block. Thus the suggestion by Japan to broaden the scope of developed countries and consider differentiating among developing countries, including graduation of developing countries, was not taken up. Instead, negotiations started to consider differentiating between various mitigation actions according to the respective capabilities of developing countries.

Developing countries have been particularly hesitant to discuss mitigation actions of their own until the US comes up with an ambitious and credible emission reduction goal. If the new President Barack Obama does substantiate his announcement for a stringent US reduction goal during the first half of 2009, negotiations on the issue may gain momentum. If, however, the US does not deliver more than the announced return to 1990 levels - even though this roughly amounts to a $20 \%$ reduction from today's levels - several other Umbrella Group countries may hide behind such a 1990 stabilization goal. This in turn may negate any ambition on the side of developing countries to deliver substantial contributions.

\section{Adaptation}

Adaption was one of the key issues in Poznan. Different aspects of the issue were discussed under almost all fora in the negotiations, including SBI and SBSTA. The mist vital negotiations dealt with the Adaptation Fund. The Adaptation Fund was already established in 2001 at COP 7 in Marrakech. ${ }^{4}$ Nevertheless, the institutional arrangements of the Adaptation Fund were only finalized in December 2007 at CMP 3 in Bali with the establishment of the Adaptation Fund Board (AFB).

The AFB functions as the operating entity of the Adaptation Fund, which shall be serviced by a Secretariat and a Trustee. ${ }^{5}$ The Global Environmental Facility (GEF) was invited to function as Secretariat and the World Bank as Trustee to the Adaptation Fund on a interim basis, to be reviewed in 2010. Building on three meetings of the AFB in 2008 and the Report of the Adaptation Fund Board, ${ }^{6}$ which included draft documents on rules and procedures and legal arrangements to be adopted by the CMP, making the Adaptation Fund fully operational was one of the main expectations from the Poznan conference.

All Parties agreed on the urgent need to operationalize the Fund in order to begin implementation of the first adaptation projects in 2009. Nevertheless, a contentious debate developed around a number of issues. In particular, the extent of financial means available to the Adaptation Fund was fiercely debated, but the issue remained unresolved in Poznan. Several operational details could only be agreed on the last day of negotiations.

The G77+China were concerned about the costs of the GEF services taking up substantial amounts of the limited finance under the Adaptation Fund and about the role of the World Bank as Trustee to the Fund. As such, the World Bank is legitimized and responsible for the monetization of Certified Emission Reductions (CERs) for the Adaptation Fund. ${ }^{7}$ Many developing countries see a conflict of interests because theWorld Bank as a whole both buys and sells CERs. In addition, some developing countries fear that theWorld Bank could try to influence priorities under the Adaptation Fund beyond its mandate as Trustee. Annex I Parties, on the other hand, welcomed the roles of the GEF and the World Bank, which are seen as experienced guarantors of quality criteria and cost-efficiency. In a meeting of the contact group, the World Bank clarified that buying and selling functions were

\footnotetext{
${ }^{4}$ UNFCCC, Decision 10/CP.7.

${ }^{5} \mathrm{FCCC} / \mathrm{SBI} / 2007 / \mathrm{L} .30$.

${ }^{6} \mathrm{FCCC} / \mathrm{KP} / \mathrm{CMP} / 2008 / 2$.

${ }^{7} \mathrm{FCC} / \mathrm{KP} / \mathrm{CMP} / 2008 / \mathrm{L} .7$.
} 
separated within the Bank. Furthermore, additional measures would be undertaken to minimize and mitigate any apparent conflicts of interest arising from the two-fold role of the Bank.

One of the two make-or-break points on adaptation, however, was that of direct access to the Adaptation Fund. ${ }^{8}$ Direct access allows eligible developing countries or Party-nominated in-country executing entities, which can include government agencies, to directly submit projects to the AFB without having to rely on intermediary organizations. Alternatively, the Fund can be accessed by going through Board-recognized implementing entities, such as UN organizations, which can submit projects on behalf of Parties. The direct access clause is a means for developing countries to ensure socalled "country-drivenness" of adaptation projects. In order to guarantee direct access for developing countries, the G77+China demanded to grant the AFB sufficient legal capacity to directly enter into contracts and fund projects. In contrast, the EU opposed extending the legal capacities of the Board, arguing in favor of a feasibility study on the legal status of the Board as suggested in the annual report of the AFB, before taking any decision. Again, the EU remained skeptical of the ability of the AFB to ensure quality and cost-efficiency in disbursement of the funds, while many developing countries feared undue influence on behalf of the GEF and/or World Bank on adaptation projects.

Since no agreement was reached in the contact group, the issue was forwarded to the ministerial level. A decision was finally made during informal negotiations, and was adopted by the CMP on Friday, 12 December. It allows direct access by eligible Parties, as well as implementing and executing entities. However the CMP decided that this advanced legal status shall be reviewed, taking into account the feasibility study commissioned by the AFB. TheWorld Bank and the GEF will nevertheless continue to act as Trustee and Secretariat, respectively, on an interim basis until review in $2010 .{ }^{9}$

The other crucial point on adaptation was the extension of the financial means of the Adaptation Fund. In particular, the G77+China called for additional andmore predictable resources to facilitate adaptation, while several developed countries also acknowledged that current financial resources are not adequate. The Adaptation Fund is currently financed by a $2 \%$ levy on CERs generated under the CDM. As of 11th August 2008, 180.2 million CERs had been issued and 3.6 million CERs were held in the Adaptation Fund CDM Account. The related amount of finance is completely inadequate compared to the adaptation needs, which amount to at least tens of billions of dollars annually in $2030 . .^{10}$

The expansion of financial means available to the Adaptation Fund was discussed as part of the Article 9 review of the Kyoto Protocol. In Poznan, the second review according to Article 9 was expected to be completed. Amongst other topics, Parties had been invited to submit their views on extending the share of proceeds from the CDM to Joint Implementation (JI) and emissions trading to increase finance for the Adaptation Fund. Five Parties submitted proposals before Poznan, and further submissions were received from accredited NGOs. ${ }^{11}$ These submissions already showed that consensus would be difficult to reach. Costa Rica and South Africa argued in favor of extending the adaptation levy to raise funds for adaptation, while Norway and France on behalf of the EU argued against it on the grounds of market inefficiency and potential disincentives to carbon trading. New Zealand also expressed skepticism about extending the share of proceeds and called for further analysis on the options of adaptation finance, as well as a clarification of the adaptation needs to be met by adaptation funding.

With such divergence in opinion, a heated debate evolved in Poznan - both within the contact group that was established on the 2nd review of the Kyoto Protocol, as well as in informal negotiations. The developing countries not only regarded extending the share of proceeds a necessity to increase finance

\footnotetext{
${ }^{8}$ Direct access to the Fund had been introduced in Decision 1/CMP.3 (FCCC/KP/CMP/2007/9/Add.1) and further developed in the Draf Provisional Operational Policies and Guidelines for Parties to Access Resources from the Adaptation Fund (AFB/B.3/8).

${ }^{9} \mathrm{FCCC} / \mathrm{KP} / \mathrm{CMP} / 2008 / \mathrm{L} .7$.

${ }^{10}$ See for instance, UNFCCC: Investment and Financial Flows to Address Climate Change. Bonn, 2007; for the 2008 update: $\mathrm{FCCC} / \mathrm{TP} / 2008 / 7$.

${ }^{11} \mathrm{FCCC} / \mathrm{KP} / \mathrm{CMP} / 2008 / \mathrm{MISC} .1$.
} 
for the Adaptation Fund; they stylized the issue as a symbol for an act of solidarity by developed countries with developing countries. The EU, Russia and Canada nevertheless continued to reject an extension of the share of proceeds, probably wanting to hold back an agreement on the issue as a bargaining chip for Copenhagen. The EU suggested to transfer the issue under the AWG-LCA and not discuss it in Poznan, because under AWG-LCA auctioning of Assigned Amount Units (AAUs) and channeling parts of the auctioning revenue into adaptation finance is being discussed in parallel (see below). Trying to find a compromise, during the second week South Africa presented a new proposal, suggesting a $2 \%$ share of proceeds on AAUs and removal units for the second commitment period of the Kyoto Protocol. The debate continued until the early hours of Saturday on the last day of negotiations, but remained without a result. This led to considerable frustration on the side of developing countries. In the closing session of the conference, several developing country Parties voiced their dissatisfaction, calling it a foregone opportunity of Annex I countries to send a strong signal of solidarity to those most affected by and most vulnerable to climate change.

Much less noted, questions on criteria for projects and the distribution of funds among developing countries were raised for the first time in Poznan. Although the issue was only touched upon in passing, it opened a vista to potential controversies among developing countries on how to share the fruits of climate related funds; namely, which country, region or community may enjoy priority access to finance and projects. Already referred to in the $3^{\text {rd }}$ meeting of the Adaptation Fund Board in Bonn and included in the CMP decision under strategic priorities is the statement that "special attention shall be given by eligible Parties to the particular needs of the most vulnerable communities". ${ }^{12}$ Yet how this "special attention" will be operationalized and ensured remains to be discussed at upcoming AFB meetings.

\section{Technology development and transfer}

Since COP13/CMP3 in Bali, the issue of technology development and transfer has seen an extraordinary rise in importance-from being an issue on the sidelines for more than a decade to becoming one of the major building blocks in current negotiations. This was achieved by developing countries. In the Bali Action Plan they managed to make their mitigation actions dependent on being "supported and enabled by technology, financing and capacity-building, in a measurable, reportable and verifiable manner", ${ }^{13}$ which is now being negotiated under the AWG-LCA. In Poznan, the AWGLCA has formed a contact group on the issue of technology development and transfer. Moreover, while technology transfer had hitherto been discussed in the SBSTA, in Bali the G77+China in addition introduced the issue into the SBI. In Poznan, SBI and SBSTA have formed a joint SB contact group on the issue.

In the months before Poznan, a large variety of submissions on technology development and transfer were sent in. The G77+China submitted a farreaching proposal on a "TechnologyMechanism under the UNFCCC", which includes the establishment of a new Subsidiary Body on Technology Transfer, a Multilateral Climate Change Fund, and a Technology Action Plan. ${ }^{14}$ Of all submissions so far, this proposal has the most comprehensive view on the issue and the most concrete proposition for the establishment of a legal framework. In contrast, the European Union's "proposals for an enhanced framework on technology" 15 are much more limited and do not include a specific design for a mechanism. Instead, they highlight parts for an enhanced framework on technology, which should include the improvement of the use of Technology Needs Assessments (TNAs), enabling

\footnotetext{
${ }^{12} \mathrm{FCCC} / \mathrm{KP} / \mathrm{CMP} / 2008 / \mathrm{L} .7$.

${ }^{13}$ FCCC/CP/2007/6/Add.1, Decision 1/CP.13, § 1c.

${ }^{14}$ Available under:

http://unfccc.int/files/meetings/ad_hoc_working_groups/lca/application/pdf/technology_proposal_g77_8.pdf.

${ }^{15}$ Available under: http://unfccc.int/files/kyoto_protocol/application/pdf/franceectechnology141108.pdf.
} 
environments and capacity building.The EU also proposes the establishment of a technology information platform.

Despite the range of submissions on the issue, progress in both contact groups in Poznan has been slow. Parties are far from having shared ideas on technology development and transfer, or even a common understanding of the issue. A "workshop on cooperation on research and development of current, new and innovative technology, including win-win solutions" conducted under the AWGLCA served for an early exchange of ideas. ${ }^{16}$

In the negotiations, the countries of the G77 defended their proposal vigorously, pointing out the urgent need to scale up financing for technologies, a strong role for public finance, and the removal of barriers to technology transfer in the form of intellectual property rights (IPRs). Europe, however, missed the opportunity to state a solid position on the issue. At first, EU countries even refused to consider the G77 proposal. By the end of the contact group sessions, theymodified their position to careful approval, with the caveat that the proposal needed to be more concrete on a number of issues, including the distribution of financial resources among the three major pillars adaptation, mitigation and technology development. Beyond this already significant gap in proposals as well as political expectations between the G77+China and the EU, a number of countries-most prominently Canada, Australia, the United States and Japan - even voiced the opinion that existing mechanisms inside and outside UNFCCC, including Official Development Aid, were sufficient to address the issue of technology development and transfer. They rejected the importance of intellectual property rights (IPRs) as a barrier for the access of developing countries to technologies needed and promoted the role of markets and the private sector in the development and diffusion of existing and new technologies.

Therefore, although half-way through the Bali Roadmap, Poznan left the negotiations on technology development and transfer remaining at an initial state. The proposals on the table, as well as the dug-in positions and widely incompatible viewpoints are far from being ready for final negotiations on crucial points; in particular the developed countries still lack a clear vision on what they want to achieve on this issue. Some movement to a clearer position may be expected from the European Union after the formation of a common EU position on technology and finance, which is expected to occur in March 2009. Their careful approximation towards the G77+China position in Poznan may mark the beginning for a more negotiable, in the end perhaps even a common position with the developing countries. This is urgently needed, as a number of developing countries have repeated their position that without significant results on the issue, they will not be ready to sign a deal in Copenhagen. Surprises, however, should be expected, because the new US administration will likely develop a strong and individual view on the role of technology development and transfer within the climate regime.

Merely on rather administrative matters some achievements were made in Poznan. The reports of the Expert Group on Technology Transfer (EGTT), ${ }^{17}$ and the review of the Terms of Reference for the review and assessment of the effectiveness of the implementation of Article 4 UNFCCC $^{18}$ passed relatively unhindered. The GEF's strategic program to scale up investment in the transfer of environmentally sound technologies ${ }^{19}$ was welcomed and renamed the "Poznan strategic programme on technology transfer, ${ }^{20}$ upon adoption by the COP. Inter alia, the proposed program entails the funding of Technology Needs Assessments (TNAs), which have the purpose to assist in the identification and analysis of priority technology needs of developing countries. Building on such TNAs, country-specific portfolios of environmentally sound technology (EST) projects and programs may be formed. Furthermore, the program serves to pilot priority technology projects linked to TNAs, and to disseminate GEF experience and successfully demonstrated ESTs.

\footnotetext{
${ }^{16} \mathrm{FCCC} / \mathrm{AWGLCA} / 2008 / \mathrm{CRP} .8$.

${ }^{17} \mathrm{FCCC} / \mathrm{SB} / 2008 / \mathrm{INF} .5-8$.

${ }^{18} \mathrm{FCCC} / \mathrm{SBI} / 2008 / 17$

${ }^{19} \mathrm{FCCC} / \mathrm{SBI} / 2008 / 16$.

${ }^{20}$ See Decision - /CP.14 Development and transfer of technologies, advance unedited version, available under: http://unfccc.int/files/meetings/cop_14/application/pdf/cp_tt.pdf.
} 


\section{Finance Mechanisms}

For too long, demands of developing countries for financial transfers, mandated by Article 4.3, 4, 5 of the UNFCCC and Article 11 of the Kyoto Protocol, have been treated with little attention. Yet, as in technology transfer, the importance of the issue has increased considerably in 2008. The FCCC Secretariat published a report on financial flows in 2007, which illustrated a huge gap between the currently available financial resources - about 25 billion USD per year - and the financial resources needed in 2030 - 130 billion USD for mitigation activites and secveral tens of billions for adaptation in developing countries only. ${ }^{21}$ An update of this report was published before Poznan. ${ }^{22}$ Furthermore, the Bali Action Plan ties mitigation actions by developing countries not only to technology transfer, but also to adequate financial support from industrialized countries. ${ }^{23}$

In 2008, a number of new multilateral and bilateral funds have already been established. These include the Clean Technology Fund and the Strategic Climate Fund/Pilot Programme for Climate Resilience by theWorld Bank, the Cool Earth Partnership by Japan, and the Spanish MDF Fund. Nevertheless, the amount of resources of these new funds is still inadequate for the scope of the challenge at hand.

In the year of negotiations between Bali and Poznan, several Parties tabled innovative proposals concerning new financing mechanisms under the UNFCCC. ${ }^{24}$ For instance, Norway proposed to withhold $2 \%$ of permits from AAUs of all Parties, and auction them directly or through a tax on issuance of the allowances; Mexico suggested a Multilateral Climate Change Fund, also called "Green Fund", to which all countries would contribute on the basis of greenhouse gas emissions, population, and gross domestic product in strict accordance with the principle of common but differentiated responsibilities and respective capabilities; and Switzerland advocated a global carbon dioxide levy of 2 USD per ton on all fossil fuel emissions. The G77+China proposed to have Annex I Parties contribute 0.5 to 1 percent of their GNP to the financial mechanisms.

The Parties also discussed basic principles that could provide a basis for determining the allocation of contributions among countries. Principles raised include, among others: equity, common but differentiated responsibilities, polluter pays, historical responsibilities, capacity to pay, effectiveness, efficiency. However, the interpretation of these principles was not universally agreed. ${ }^{25}$ Most developing countries argued that financing should come from Annex I countries based on these principles, while Mexico used the principles to argue for contributions from all countries. Several industrialized countries highlighted the importance of funds channeled through the private sector, including market mechanisms and foreign direct investments. In the end, Parties did not make any progress on this issue under the AWG-LCA.

Parties in Poznan also discussed improving work under the Least Developed Countries Fund (LDCF), which is operated by the GEF. In particular, options for speeding up the process of implementing "national adaptation programmes of action" (NAPAs) were discussed. NAPAs help to identify priority activities with regard to climate change adaptation. LDCs expressed their concerns on the time theNAPA process takes and its complicated process, which contradicts the "urgent and immediate needs of LDCs to adapt to the adverse impacts of climate change". ${ }^{26}$ As to date, the total financial volume of the fund, donated on a voluntary basis, is about 172 million USD, LDCs further claimed that these resources are insufficient. For the next four years further funds shall be obtained to reach 500 million USD; this is the amount estimated by the FCCC Secretariat needed to finance NAPA

\footnotetext{
${ }^{21}$ See above, note 10 .

${ }^{22} \mathrm{FCCC} / \mathrm{TP} / 2008 / 7$.

${ }^{23}$ For more detailed analysis on the Bali Action Plan, see also Watanabe, Rie/Arens, Christof/Mersmann, Florian/Ott, Hermann, E./Sterk, Wolfgang: The Bali Roadmap for Global Climate Policy. New Horizons and Old Pitfalls. Journal for European Environmental \& Planning Law. Vol. 5 No. 2, 2008:139-158.

${ }^{24}$ See FCCC/AWGLCA/2008/MISC.2, FCCC/AWGLCA/2008/MISC.5 and Add.1.

${ }^{25}$ Regarding the details of principles, see Rie Watanabe. 2008. Who should Pay for Climate Protection? Another Side of the Same Coin of Burden Sharing. Back to Legal Principles, available at www.wupperinst.org.

${ }^{26}$ UNFCCC, Decision 28/CP.7.
} 
implementation. $^{27}$

The conclusions finally adopted include an annex with further guidance on the operation of the LDCF. ${ }^{28}$ Several of the concerns of LDCs were taken up, yet only with a weak mandate: the GEF is asked to raise awareness of the need for adequate and predictable resources under the LDCF and Parties are invited to continue contributing to the LDCF. The GEF is requested to work more closely with its agencies to improve communication with LDCs, and to expedite the process. Progress and experiences gained from implementing the least developed countries work program shall be discussed at the thirty-third meeting of the SBI.

\section{The Clean Development Mechanism}

As usual, the Clean Development Mechanism (CDM) occupied much of the conference's attention, being discussed in no less than five agenda items. While the CDM continues to grow rapidly, there are ever more voices now doubting the environmental integrity of the mechanism. Several studies and reports have claimed that the CDM approval process was failing to effectively screen out projects that are actually not additional but would also have taken place without the CDM. ${ }^{29}$ At its last meeting of the year just before the CMP, the CDM Executive Board (EB) had actually suspended the accreditation of one of the validators (Det Norske Veritas), a move that sent a shock wave through the market.

Therefore, the EU in particular suggested significant governance reforms, such as shifting the selection and payment of the validators from the project participants to the FCCC Secretariat in order to guard against conflicts of interest on the side of the validators. The EU also suggested that the dayto-day operation of the CDM should be shifted from the Executive Board, which is meeting only bimonthly and stretched to capacity, to the FCCC Secretariat, and to develop a code of conduct for EB members to prevent conflicts of interest. A further issue was the development of an appeals procedure to enable project participants to challenge decisions by the EB. Many of these suggestions were resisted by developing countries, however. Many of them do not trust the Secretariat, as they perceive it to be dominated by staff from industrialized countries.Others demanded a "streamlining" rather than further tightening of the rules, pointing to delays in the project registration process and unpredictability in EB decisions.

This year, the complexity of the CDM agenda was increased further since it was discussed under two agenda items: the agenda item dealing with the annual report of the EB and the Article 9 review. As noted above (section on adaptation), the Article 9 review, in the end, was concluded without a decision due to the controversy about extending the share of proceeds for adaptation. In the decision on the EB report, Parties finally agreed that the EB should speed up its procedures and emphasize its executive role, including through making effective use of its support structure, including its panels, other outside expertise, and the Secretariat. The CMP also requested the EB to increase the transparency and consistency of its decision-making and to strengthen its direct communication with project participants.

The hope for improving the environmental integrity of theCDMeminently rests on the Validation and Verification Manual (VVM) that was adopted by the EB this year. Its purpose is to provide clearer

\footnotetext{
${ }^{27} \mathrm{http}: / /$ www.thegef.org/uploadedfiles/LDCF/LDCF_insert_LDCF.pdf.

${ }^{28} \mathrm{FCCC} / \mathrm{SBI} / 2008 / \mathrm{L} .21$ and Add.1.

${ }^{29}$ E.g. Michaelowa, Axel/Purohit, Pallav: Addionality determination of Indian CDM projects. Can Indian CDM project developers outwit the CDM Executive Board? London: Climate Strategies, 2007; Schneider, Lambert: Is the CDM fulfilling ist environmental and sustainable development objective? An evaluation of the CDM and options for improvement. Berlin: Öko-Institut, 2007; Wara, Michael W./Victor, David G.: A Realistic Policy on International Carbon Offsets. PESD Working Paper No. 74. Stanford University Program on Energy and Sustainable Development, 2008.
} 
guidance to the validators on how to assess projects. The CMP requested the EB to maintain and regularly update the VVM and to carry out outreach and implementation activities. In addition, the CMP requested the EB to develop and apply a system for continuous monitoring of the validators and to regularly publish statistics on their performance on its website, to develop and apply measures to ensure that the validators comply with the requirements and to finalize a framework to address noncompliance by validators, including through sanctions. The EU's suggestion to have the validators paid by the Secretariat was reduced to a request to the EB to analyze means to enhance the impartiality and independence of the validators.

Much of the criticismin the scientific literature and fromNGOs has focused on the subjectivity involved with the current approach of project assessment. The CMP therefore requested the EB to enhance the objectivity of approaches to demonstrate additionality, including through standardized methods to calculate financial parameters, quantitative approaches to the demonstration of barriers and better definition of common practice. As a further means to enhance the objectivity of methodologies, the EU suggested that greater use should be made of benchmarks to establish additionality and baseline emissions. While this approach was supported by some developing countries such as Argentina, it was opposed by others such as Brazil, China, India, and South Africa. The opponents feared that a benchmark approach would lead to the imposition of standards fromoutside. The final decision text therefore only requests the $\mathrm{EB}$ to enhance the objectivity in the determination of baselines, but without any specific suggestions. Overall, while efforts to improve the environmental integrity of the CDM did not go as far as suggested by the EU and environmental organizations, the CMP did agree on steps to increase the oversight of the validators and improve the objectivity of project development and assessment.

The regional distribution ofCDMprojects once again proved to be a highly controversial issue. The four largest host countries-India, China, Brazil, and Mexico-account for no less than 3/4 of all projects, whereas many other countries have so far been completely bypassed. African countries and LDCs, with support by the EU, therefore suggested that the project registration process should be streamlined for countries with significant underrepresentation, that the EB should facilitate the development of methodologies with potential for application in such countries, and that Parties should support the development of projects in these countries. Yet countries such as Colombia and Saudi Arabia maintained that no special preference should be given to particular groups of countries. In the end, the geographical focus was taken out with regard to the development of methodologies, while efforts to streamline the process and promote project development are still to take into account especially LDCs, SIDS and Africa.

The future of the flexible mechanisms is being discussed under the AWGKP, as the mechanisms are one of the means available to industrialized countries to meet their targets. Last year's discussions had yielded a long list of options how to reform the mechanisms post-2012 that had been proposed by Parties. The options range from including CCS and nuclear power in the CDM, via sectoral crediting approaches and benchmarking to discounting of CERs and differentiating among the host countries. ${ }^{30}$ Shortly before Poznan, the Chair had issued another text attempting to flesh out the options further. ${ }^{31}$ The discussions in Poznan did not deal with substantive issues but revolved around the further process in 2009. Parties agreed on a round of submissions by Parties with the deadline on February 6. On this basis, the Chair is requested to produce a new text for consideration at the March meeting of the AWG-KP. ${ }^{32}$

\footnotetext{
${ }^{30} \mathrm{FCCC} / \mathrm{KP} / \mathrm{AWG} / 2008 / \mathrm{L} .12$.

${ }^{31} \mathrm{FCCC} / \mathrm{KP} / \mathrm{AWG} / 2008 / \mathrm{INF} .3$

${ }^{32} \mathrm{FCCC} / \mathrm{KP} / \mathrm{AWG} / 2008 / \mathrm{L} .19$.
} 


\section{Reducing Emissions from Deforestation and Forest Degradation (REDD)}

According to the IPCC, deforestation and forest degradation activities, mainly in tropical areas, have accounted for $5.8 \mathrm{Gt}$ CO2 per year since the 1990 s, roughly $20 \%$ of all global greenhouse gas emissions. Parties have agreed that a post-2012 agreement needs to address this issue, in order to comply with Article 2 of the UNFCCC. However, it was only at COP11 in Montreal in 2005 when forests were taken up under the Convention at the request of Papua New Guinea, Costa Rica and eight other Parties, under a new agenda item. With wide support from Parties at COP11, a contact groupwas established and a process to explore options for REDD began. The Bali Roadmap includes reference to REDD and requested the SBSTA to undertake a program of work on outstanding methodological issues related to a range of policy approaches and positive incentives for REDD. ${ }^{33}$

In 2008, progress was made regarding methodological problems. The FCCC Secretariat organized a workshop in Tokyo as part of the SBSTA work. It featured discussions on establishing reference emission levels, scale of implementation, and options for assessing the effectiveness of actions. In the run-up to Poznan, a number of Parties submitted proposals on REDD. These proposals relate to measurable, reportable and verifiable mechanisms, addressing the risks of leakage and nonpermanence and aiming at ensuring the integrity of baselines and additionality of emissions reductions. Many countries are already preparing for REDD and several are signing partnership agreements on support for it. During the Poznan conference, Brazil presented a climate plan that for the first time lays out a set of quantified targets to bring down the rate of forest clearances by 70 percent by 2018, with respect to the average rate from the baseline period 1996-2005.

However, no decision was taken on the nature of policy approaches and their concrete mechanisms in Poznan; these decisions were left to COP15/CMP5 in Copenhagen. Discussions in Poznan mainly focused on the participation of indigenous peoples in the policy approaches to be implemented and on the role of conservation and sustainable management of forests.

Parties discussed the participation of indigenous peoples at length, as it relates to a broader socioeconomic perspective. Bolivia, the European Union, Norway, Mexico, Switzerland and others referred explicitly to the rights of indigenous peoples and to the UN Declaration on the Right of Indigenous Peoples. The US, Canada, Australia and New Zealand, however, opposed this. The final decision recognizes "the need to promote the full and effective participation of indigenous people and local communities and ... [notes] relevant international agreements." ${ }^{34}$ The reference to indigenous "people" instead of "peoples", aswell as the removal of theword "rights" fromthe original draft provoked harsh protests by human rights groups and environmental NGOs. Moreover, in the final plenary, Denmark emphasized its 'well known position on rights of indigenous peoples as also recognized in the UN Declaration on the Rights of Indigenous Peoples, adopted in September 2007'.

Parties also discussed the relevance of biodiversity within actions for REDD. The EU stressed the important role REDD mechanisms can play to foster biodiversity. In the TokyoWorkshop, Parties had noted that good policy design ensured the promotion of co-benefits such as biodiversity. In turn, cobenefits were often the main drivers of positive changes in forest policies. ${ }^{35}$ But the final SBSTA decision failed to explicitly refer to the importance of REDD for biodiversity due to resistance of the Umbrella Group.

In addition, the decision calls for the Chair of the SBSTA to hold an expert meeting on methodological issues relating to, among other things, REDD "in developing countries, and the role of conservation, sustainable management of forests, and enhancement of forest carbon stocks in developing countries". This reference to forest conservation was another controversial issue. The

\footnotetext{
${ }^{33}$ UNFCCC, Decision 2/CP.13.

${ }^{34} \mathrm{FCCC} / \mathrm{SBSTA} / 2008 / \mathrm{L} .23$.

${ }^{35}$ FCCC/SBSTA/2008/11.
} 
text was taken from the Bali Action Plan, where the relevant subclause had been separated from the previous by a semicolon. In Bali, India and other Parties had advocated including forest conservation in REDD. India, who has a long record on strong conservation measures, suggested to reward Parties for efforts to stop deforestation in the past, while others feared this would probably result in taking away resources from future actions. In Poznan, India and other Parties called for replacing the semicolon by a comma in order to underscore the importance of conservation, a move that prevailed. In the end, the above mentioned compromise text was agreed upon. Finally, the decision calls for the Secretariat to estimate the cost of implementing methodologies and monitoring systems and invites Parties and observers to submit their views on issues relating to indigenous people and local communities for the development and application of methodologies, thus once more referring to "people" instead of "peoples".

\section{Summary and outlook}

COP14/CMP4 in Poznan saw movement on a few issues in the negotiations. On adaptation, Poznan delivered the full operationalization of the Adaptation Fund. This includes an improvement of the legal capacity of the Adaptation Fund Board (AFB), which developing countries had vigorously asked for. Countries may now directly submit projects to the AFB without having to rely on intermediary organizations. Regarding the CDM, Parties agreed that the CDM Executive Board should speed up its procedures and emphasize its executive role. Furthermore, it shall analyze means to enhance the impartiality and independence of the validators and enhance the objectivity in the determination of baselines.Onmitigation, Poznan delivered an agreement that future commitments should principally take the form of quantified emission limitation and reduction objectives. Conclusions for both the AWG-LCA and the AWG-KP mandate the respective Chairs to develop draft negotiating texts during the first half of 2009 and draft decision texts until June $2009 .{ }^{36}$

Given that about nine thousand people attended the Poznan conference, of which several thousands were delegates, these outcomes are indeed pretty meager. In the two building blocks technology transfer and finance, literally no results were achieved despite the enormous importance of these issues for a successful outcome inCopenhagen.Negotiations on the formerwere hampered by lack of a shared vision on North-South technology cooperation, whereas negotiations on finance were mainly blocked by the developed countries: They held back any offers or decisions until final negotiations in Copenhagen. Following the same South-North pattern, developing countries did not succeed to extend the share of proceeds for the Adaptation Fund.On mitigation, besides the minor agreements mentioned above, none of the big issues was moved any further. Umbrella Group countries continued to reject an aggregate target for Annex I Parties, and the relationship between the aggregate target and individual commitments remains unclear. The same goes for the CDM: the larger issues were left at the sidelines. For instance, no progress was made on the future reform of the CDM, and efforts to improve the environmental integrity of the CDM did not get far. Lastly on REDD, Poznan even witnessed a significant backlash since the final language excludes important references to indigenous peoples rights' and to biodiversity.

Thus no doubt, the outstanding tasks for the coming year are immense. In order to work successfully, both Ad hoc Working Groups must shift into full negotiating mode. The AWG-LCA will have to finalize an agreement on all four building blocks, including a shared vision on mid- and long-term global emission reduction goals. As it is the only body where all countries, including the US and developing countries, participate in discussions on mitigation, it must tackle the steadily increasing rift between developing country and developed country interests. Issues like technology transfer, finance, and the indicators "measurable, reportable, verifiable (MRV)" will have to be spelled out in precise language in order to reach agreement on other issues. Likewise, the AWG-KP has a full agenda to be

\footnotetext{
${ }^{36}$ FCCC/AWGLCA/2008/L.10; FCCC/KP/AWG/2008/L.19.
} 
worked through. In particular, the ambition and comparability of mitigation efforts by developed countries will be central if the legacy of Kyoto to define "targets and timetables" shall live on. And much to the contrary of the past, the issue of adaptation must no longer be treated as a secondary item, but needs to be treated on equal terms to other building blocks.

Participants left Poznan without any clarification on the kind of legal outcome aimed at in Copenhagen.Will negotiations in the AWG-KP result in an amendment, or rather a follow-up to the Kyoto Protocol?Will negotiations in the AWG-LCA deliver a new legal instrument, such as a "Copenhagen Protocol", which may also incorporate the outcomes from the AWG-KP? Or will they only take the form of less manifest CMP decisions, as is preferred by many developing countries?

In light of the sheer scope of the negotiations agenda and the current absence of political leadership by developed countries, including the European Union, doubts arise on whether Parties will at allmanage to reach a comprehensive deal in Copenhagen. There is a growing risk that Copenhagen might only deliver a basic framework text not ready for ratification, and that somemore years of negotiationsmay be needed before a new accord would be ready for ratification and subsequent entry into force. In the end, this would mean that pressure on national governments to implement stringent emissions reductions programs would be delayed as well. Keeping a rise in global temperature below the dangerous threshold of 2 degrees Celsius would then become rather unlikely.

There is, however, some room for hope. After years of obstruction and a big sleep on climate policy, the United States will eventually return back to the scene. Since his election as president, Barack Obama has repeatedly promised to make climate change a high priority issue during his term. It can be expected that the new US administration with it's highly qualified leaders on energy and environmental issues will significantly mold national and international climate policy development in the future, especially now that the EU seems to have abdicated from its leadership role. On the last days of Poznan, Senator John Kerry transmitted a letter assuring that Obama would try his best to make signing a deal in Copenhagen possible. There are hopeful signs that the new US administration will seize the opportunity to combine a fight against the economic crises with a greening of the economy. This could lead to a hitherto unseen unleashing of forces for the advancement of renewable energy and energy efficiency - and catapult the US into the leadership position on climate change that President Obama aspires.

Yet even if the US will return as a driving force, this does not imply that a comprehensive deal in Copenhagen is certain. Many developing countries are still waiting for concrete signs and acts of trustbuilding before they are prepared to contribute domestic mitigation actions by themselves. This is where Parties are caught in a vicious circle of their own making:Without clear leadership by the developed countries, developing countries are not going to contribute; but without significant contributions by the developing world, in particular by rapidly industrializing countries, real ambition on the side of the US and other industrialized countries is impossible to achieve. The North cannot solve the problem without the engagement of the South, but the South will only contribute if the North demonstrates clear leadership and provides adequate support.

The analysis after the adoption of the Bali Road Map thus remains up to date and the hopes that have been expressed unfulfilled: Getting out of the 'climate trap' requires a new understanding of the deep interconnectedness between the interests and fates of South and North. ${ }^{37}$ Climate change is not a zerosumgame but an endeavour where all sides will either win or lose together. Climate diplomacy thus must proceed from adversarial geopolitical strategies to forward-looking co-operative approaches that take the legitimate interests of their counterparts into account and search for common ground.

Having said this, however, the first and foremost duty to resolve this impasse lies with the developed world. For reasons of historical responsibility and economic capacity it can be expected that the more affluent countries assembled under the heading "Annex I" in the climate regime make the first step.

\footnotetext{
${ }^{37}$ Ott, Hermann E./ Sterk, Wolfgang/Watanabem Rie: The Bali roadmap: new horizons for global climate policy; in; Climate Policy 8 (2008), pp. 91-95.
} 
This first step must take two forms: A clear commitment to adequate reduction targets in the range indicated by the IPCC and meaningful, convincing offers regarding financial and technological assistance to developing countries. The importance of resolving the technology and finance package therefore cannot be overestimated. In order to achieve progress, however, these issues must be taken out of the realm of technical expertise and handed over to political decision-makers.

There have been numerous examples in Bali and Poznan that a generous offer by developed countries would be met with great sympathy by developing countries. But the window of opportunity is closing quickly as the positions become more and more entrenched. South Africa, Mexico, South Korea, and other developing countries demonstrated considerable spirit of determination and an honest ambition to fight global warming in Poznan. In the spirit of hope and change stipulated by the new US President it appears possible that these examples will have a positive impact on other countries of the South and eventually lead up to a joint leadership initiative of Southern and Northern Parties in the run up to Copenhagen. 